\title{
Extinction following intracranial reward: Frustration or drive decay?'
}

JAAK PANKSEPP AND JAY TROWILL, DEPARTMENT OF PSYCHOLOGY, UNIVERSITY OF MASSACHUSETTS, Amherst, Massachusetts 01002

Rats trained to press a bar for intracranial reinforcement underwent repeated extinctions and reacquisitions. The first five extinction periods were immediately preceded by a reinforcement period. The last extinction session occurred $24 \mathrm{~h}$ after the last reinforcement period. Extinction scores were higher during this session than during the previous ones. This proactive effect of reinforcement training on subsequent extinction is incompatible with the drive decay theory of self-stimulation, but is consistent with an interpretation of frustration produced by non-reward.

Fourteen years of dispute have not resolved whether intracranial reinforcement (ICR) truly has properties that distinguish it from conventional reinforcers. A crucial difference in the behaviors evoked by the two types of reinforcers is the rate of extinction when reinforcement is withheld (Seward, Uyeda, \& Olds, 1959; Deutsch, 1963; Gallistel, 1964). Responses rewarded by ICR have been reported to extinguish more rapidly than those maintained by either food or water reinforcement (McIntyre \& Wright, 1965; Culbertson, Kling, \& Berkeley, 1966). To explain this difference Howarth \& Deutsch (1962) proposed a theory stating that the application of electrical stimulation to rewarding areas of the brain stimulates drive and reinforcement systems simultaneously. Since this drive is assumed to decay following the removal of ICR, extinction is rapid.

Before this interpretation could be accepted, the differences between the typical ICR situation and conventional reward situations had to be controlled. Such considerations led to experiments which suggested that the differences between the two types of rewards were merely due to one of the following: the incomparability of one ICR and a unit of conventional reward (Pliskoff, Wright, \& Hawkins, 1965); the manner of reward presentation (Gibson, Reid, Sakai, \& Porter, 1965); the deprivation levels at which Ss were tested (Panksepp \& Trowill, 1967).

A recent study by Quartermain \& Webster (1968) has, however, presented compelling evidence for the acceptance of a drive-decay explanation of ICR based behavior. Quartermain and Webster showed that extinction after continuously reinforced bar pressing was dependent on the activity level of the animals. When extinction was measured immediately after a reinforcement period, ICR and water rewarded animals gave an equal number of responses. However, the animals receiving ICR were found to be more active at the start of the extinction session than were the water rewarded animals. If extinction was measured $1 \mathrm{~h}$ after a reinforcement period when the activity levels of the two groups of animals were the same, water rewarded Ss responded significantly more than intracranially rewarded Ss. This finding is similar to what has previously been called the extinction without responding effect (Howarth \& Deutsch, 1962). This extinction after ICR is dependent on the time since the last reinforcement but independent of the number of responses made. The following study, using a procedure similar to that used by Quartermain \& Webster (1968), suggests that frustration, rather than the drive-decay engendered by removal of reward, best explains ICR extinction data.

Method

Seven male rats were implanted unilaterally with stainless steel bipolar electrodes aimed at the medial forebrain bundle. All electrodes were histologically confirmed to lie in the medial forebrain bundle at the level of the ventromedial nucleus. Each pole of an electrode was $0.23 \mathrm{~mm}$ in diameter and insulated except at the tip. Each ICR consisted of a $0.5 \mathrm{sec}$ train of 60-cycle alternating current of 20 to 40 microamperes, individually adjusted for each rat. A single-lever operant conditioning box, 24 x $20 \times 19 \mathrm{~cm}$, served as the experimental chamber. Ss were maintained on ad lib food and water throughout the experiment.

During pretraining animals were screened for self-stimulation. At least a week was allowed between pretraining and the start of testing. Throughout testing all Ss were run under identical conditions: on Day 1 each $S$ was allowed 500 continuously reinforced responses; on Day 2, 250 reinforced responses were allowed followed by a 15 -min extinction period during which unreinforced responses were recorded. This two day sequence was repeated five times with one day between each repetition. During the sixth and final sequence the 15 -min extinction period followed the 250 reinforcements by $24 \mathrm{~h}$. At the start of all sessions, except the final extinction session, Ss were placed in the experimental chamber and allowed $2 \mathrm{~min}$ to start bar-pressing. If responding did not start within this interval, free stimulations (priming) were given until the $S$ started responding.

Results and Discussion

Table 1 shows the session-by-session extinction scores for all Ss. During the first five sessions all Ss except one (Rat No. 1) developed a pattern of responding whereby priming stimulations were never necessary. $S 1$, however, required priming at the start of every session. Of the six Ss that did not require priming, four had their highest extinction score during the last session when no self-stimulation preceeded extinction. This result is compelling, though it does not reach statistical significance $(p=.2)$ with the sign test (Siegel, 1956) when the null hypothesis is that extinction during the sixth session should not be different than the highest individual scores for Sessions 1-5. This lack of difference, however, is strong evidence against a drive decay interpretation of ICRbased extinction. In fact, when the present data are tested against predictions derived from the drive-decay theory (Deutsch, 1963), the drive-decay hypothesis has to be rejected. The drive-decay theory would predict that extinction scores should be lowest when not preceded by a self-stimulation session. Thus when the data are compared to the conservative hypothesis that most (75\%) of Ss run under present conditions should not give the highest score during the sixth session, the results are contrary to a drive-decay hypothesis at the .01 level.

Although the present study contained too few Ss to make the sixth extinction session statistically different from the first five sessions, the striking tendency for Ss that required no priming to exhibit the most resistance to extinction on the sixth session cannot be ignored. For instance the large increase in resistance to extinction exhibited by Ss 2 and 5 cannot be attributed to chance variability. These data, then, are contradictory to that presented by Quartermain \& Webster (1968). There are at least two possible causes for this difference: (1) Quartermain and Webster did not report which animals required priming and which did not. Qualitative differences in the behavior of these two types of animals suggests that pooling, if it did occur, is invalid; (2) The

Table 1

Individual Extinction Scores

for Seven Ss during Six 15-min Extinction Sessions.

The first five sessions were immediately preceded by reinforcement. The sixth session followed the reinforcement period by $24 \mathrm{~h}$.

\begin{tabular}{crrrrrrr} 
Extinction & \multicolumn{8}{c}{ Rats } & & & \\
Session & 1 & 2 & 3 & 4 & 5 & 6 & 7 \\
\hline 1 & 30 & 53 & 22 & 33 & 47 & 11 & 18 \\
2 & 31 & $55^{*}$ & $22^{*}$ & 44 & 41 & $19^{*}$ & 29 \\
3 & 8 & $32^{*}$ & $13^{*}$ & 26 & $34^{*}$ & $17^{*}$ & 36 \\
4 & 12 & $34^{*}$ & $25^{*}$ & $22^{*}$ & $59^{*}$ & $12^{*}$ & 13 \\
5 & 7 & $23^{*}$ & $16^{*}$ & $40^{*}$ & $38^{*}$ & $12^{*}$ & $32^{*}$ \\
6 & 1 & $133^{*}$ & $30^{*}$ & $15^{*}$ & $79^{*}$ & $27^{*}$ & $33^{*}$ \\
\hline
\end{tabular}

*Sessions during which priming was not necessary 
repeated extinctions and reacquisitions in our experiment defined the situation more explicitly to the animal (i.e. Ss should have developed an expectancy of beginning each session with selfstimulation)

This study shows that the simple manipulation of delaying extinction can increase the subsequent extinction score. Likewise it has been shown that experience with special training conditions can abolish the extinction without responding effect (Pliskoff \& Hawkins, 1963) and can prolong extinction responding (Gandelman, Panksepp, \& Trowill, 1968; Herberg, 1963; Pliskoff, Wright, \& Hawkins, 1965; Stutz, Lewin, \& Rocklin, 1965). Such data can be explained in terms of frustration theory.

In contrast to the drive-decay hypothesis, frustration theory (Amsel, 1962) predicts that extinction occurs as a result of the development of competing responses induced by the frustration of not receiving a reward when one is expected. It is further postulated that the frustration engendered by nonreward is directly related to the incentive value of the discontinued reward. Since incentive motivation depends on the most recent conditions of reinforcement (Bolles, 1967), frustration should be greatest and extinction should be fastest, when extinction is measured immediately after a period of reinforcement. Since ICR can be considered as a reward of high incentive value, the frustration engendered after its removal should be high and the extinction score should be correspondingly low. Until the sixth extinction period of the present study all animals had had a history of beginning each session with reinforcement. Thus, during these five extinction sessions, frustration was produced by two usually highly correlated sources: (1) the abrupt removal of reward; and (2) the failure to confirm a learned expectancy. During the sixth session, the high expectancy of being rewarded, coupled with the absence of frustration from removal of reward, produced a high extinction score.

Finally, it should be noted that the Quartermain and Webster study highlights a problem of methodology in direct comparisons of ICR and conventional rewards. Quartermain and Webster compared Ss on ad lib water receiving ICR as reward to water deprived Ss receiving water. Under such drive conditions they demonstrated extinction without responding in the ICR rewarded animals. Evidence for extinction without responding has been presented for conventional rewards, but only under conditions where Ss, maintained on ad lib food and water, had been willing to respond for a high incentive food reward (Panksepp \& Trowill, 1967). This suggests that Quartermain and Webster were actually demonstrating satiation-specific, rather than reward-specific, behavior. We feel that unless the neural tissue under the stimulating electrode can be verified to be specific to a certain drive, comparisons between conventional rewards and ICR are invalid unless behavioral measures for both rewards are taken under low deprivation conditions. Furthermore, if ICR is to be considered as a reward of high quality, realistic comparisons between ICR and food should use tasty food rewards rather than such drab fare as dry rat pellets and water.

\section{REFERENCES}

AMSEL, A. Frustrative nonreward in partial reinforcement and discrimination learning: Some recent history and a theoretical extension. Psychol Rev., 1962, 69, 306-328.

BOLLES, R. C. Theory of motivation. New York: Harper \& Row. 1967.

CULBERTSON, J. L., KLING, J. W., \& BERKLEY, M. A. Extinction responding following ICS and food reinforcement. Psychon. Sci., 1966, 5, 127-128.

DEUTSCH, J. A. Learning and electrical self-stimulation of the brain. $J$. Theor. Biol, 1963, 4, 193-214.

GALLISTEL, C. R. Electrical self-stimulation and its theoretical implications. Psychol Bull, 1964, 61, 23-24.

GANDELMAN, R., PANKSEPP, J., \& TROWILL, J. A. The effect of lever retraction on resistance to extinction of a response rewarded with electrical stimulation of the brain. Psychon. Sci., 1968, 10, 5-6.

GIBSON, W. E., REID, L. D., SAKAI, M., \& PORTER, P. B. Intracranial reinforcement compared with sugar-water reinforcement. Science, 1965, $148,1357-1358$.

HERBERG, L. J. Determinants of extinction in electrical self-stimulation. $J$. comp. physiol. Psychol, 1963, 56, 686-690.

HOWARTH, C. I., \& DEUTSCH, J. A. Drive decay: the cause of fast "extinction" of habits learned for brain stimulations. Science, 1962, 137, 35-36.

McINTYRE, R. W., \& WRIGHT, J. E. Differences in extinction in electrical brain-stimulation under traditional procedures of reward presentation. Psychol Rep., 1965, 16, 909-913.

PANKSEPP, J., \& TROWILL, J. A. Intraoral self injection: II. The simulation of self-stimulation phenomena with a conventional reward. Psychon. Sci, $1967 \mathrm{~b}, 9,407408$.

PLISKOFF, S. S., \& HAWKINS, T. D. Test of Deutsch's drive-decay theory of rewarding self-stimulation of the brain. Science, 1963, 141, 823-824.

PLISKOFF, S. S., WRIGHT, J. E., \& HAWKINS, T. D. Brain stimulation as a reinforcer: intermittent schedules. J. exp. Anal Behav., 1965, 8, 75-88.

QUARTERMAIN, D., \& WEBSTER, D. Extinction following intracranial reward: the effect of delay between acquisition and extinction. Science, $1968,159,1259-1260$.

SEWARD, J. P., UYEDA, A. A., \& OLDS, J. Resistance to extinction following cranial self-stimulation. J. comp. physiol. Psychol, 1959, 52, $294-299$.

SIEGEL, S. Nonparametric statistics. New York: McGraw-Hiil, 1956.

STUTZ, R. M., LEWIN, I., \& ROCKLIN, K. W. Generality of "drive-decay" as an explanatory concept. Psychon. Sci, 1965, 2, 127-128.

NOTE

1. This work was partially supported by USPHS Grant No. MH 13155-02 awarded to Jay A. Trowill. 